\title{
Insumos ecológicos en la serigrafía textil: Caso peruano
}

\begin{abstract}
RESUMEN
La serigrafía textil utilizada por las microempresas y pequeñas empresas (MYPE) del Perú se caracteriza por ser artesanal, lo que supone que utilizan tecnologías limpias, sin embargo, no utilizan insumos ecológicos.

El Perú es un país rico en tradición en el uso de tintes naturales desde las culturas preincas e incas. En la actualidad dicha tradición se encuentra limitada a prendas elaboradas para los turistas extranjeros y en lugares muy alejados y de difícil acceso.

En los ensayos realizados para obtener un tinte natural para el proceso de estampado se han hecho pruebas con el eucalipto (Eucalyptus), y se han obtenido buenos resultados con el sistema constituído por el concentrado de hojas de eucalipto y almidón como vehículo.
\end{abstract}

Palabras clave: Insumos ecológicos, serigrafia textil, microempresas, tintes naturales.

\section{ECOLOGICAL INPUTS IN SILK SCREEN PRINTING: PERUVIAN CASE \\ ABSTRACT}

The silk screen printing used by the micro and small businesses (MYPE for its acronym in Spanish) of Peru, is characterized for being artisanal, which means that they use clean technologies, however, they don't use ecological inputs.

Peru is a rich country in the tradition of use of natural inks from the time of inca and preinca's cultures. At present mentioned tradition is limited to clothes elaborated for foreign tourists and in far places of difficult access.

In the essays made to obtain a natural ink for the printing process, tests have been made with eucalyptus (Eucalyptus), getting good results with the system consisting of the extract of eucalyptus leaves and starch as vehicle.

Key words: Ecological inputs, silk screen printing, micro businesses, natural inks.

\section{INTRODUCCIÓN}

El clima de nuestro planeta se verá alterado significativamente si se continúa manteniendo la cultura de no protección a nuestro medio ambiente. El calentamiento global debido al uso de combustibles fósiles y a otros procesos industriales (dióxido de carbono, metano, óxidos nitrosos y clorofluorocarbonos), está provocando la intensificación del efecto invernadero y el consecuente aumento de la temperatura global, el derretimiento de los hielos polares y el aumento del nivel de los océanos, esto amenaza con la vida en el planeta de una manera radical y sin vuelta atrás.

El acuerdo normativo internacional se encuentra en la Convención Marco de las Naciones Unidas sobre el Cambio Climático (CMNUCC), suscrita en 1992 en la Cumbre de la Tierra de Río de Janeiro, en donde se acordaron medidas referentes al cambio climático, diversidad biológica y la declaración de principios forestales. En el Protocolo de Kyoto (1997) se dieron normas vinculantes para la reducción de emisiones contaminantes. En el Acuerdo de Copenhague se estableció que todos los estados reducirán sus emisiones, pero no es vinculante.

En la cultura peruana, en especial de las MYPE, las preocupaciones son mínimas, en lo referente al calentamiento global los desperdicios de los procesos productivos son eliminados en botaderos comunes sin tener como alternativa el reciclaje.

En un mercado globalizado y competitivo, el uso de nuevas tecnologías asistidas por computador, la mentalidad de cambio permanente, estructuras organizativas flexibles, colaboración y asociación con otras empresas para conseguir objetivos comunes y orientación de la organización hacia una cultura de calidad y el servicio al cliente, permiten obtener ventajas competitivas, lo cual no es aprovechado por las empresas que se dedican a la serigrafía textil.

La capacitación y creación de la cultura ecológica es mínima en este sector productivo, por lo que es necesario que exista un vínculo entre la universidad y las MYPE de manera que se cambien dichos hábitos y se cumpla su rol social.

\footnotetext{
Ingeniero Industrial. Docente Asociado. Facultad de Ingeniería Industrial UNMSM. E-mail: orojasla@hotmail.com

2 Magister. Docente Principal. Facultad de Ingeniería Industrial UNMSM E-mail: danielmavila@yahoo.es

3 Licenciada en Química. Docente Asociada. Facultad de Química e Ingeniería Química UNMSM. E-mail: norarpc@hotmail.com
} 


\section{MARCO TEÓRICO}

Hay colorantes directos o sustanciales que se adhieren directamente a la fibra textil y colorantes que requieren la presencia de sustancias químicas (fijadores) para realizar el teñido. El porcentaje de colorante y mordiente en el teñido es importante para la obtención de colores intensos y sobre todo perdurables.

Según Gómez (4), los taninos tienen las siguientes propiedades relacionadas a colores: los taninos en contacto con sales de hierro, producen combinaciones fuertes de los colores azul o verde oscuro y son poco solubles en agua. Las soluciones de tanino precipitadas con sales metálicas (hierro, cobre, plomo, estaño, mercurio, etcétera) y forman compuestos de colores pardos con soluciones de bicromato de potasio y ácido crómico. Las soluciones de los taninos son precipitados por diversas sustancias básicas tales como: colorantes orgánicos básicos, el agua de cal, el agua de barita, los alcaloides, etcétera: Las soluciones de tanino expuestas al aire absorben el oxígeno y rápidamente toman colores oscuros.

Gibaja (3) menciona que los antiguos peruanos fueron grandes tejedores y tintoreros que utilizaron los pigmentos de las plantas y animales para obtener colores vistosos y brillantes, desde el amarillo y el rojo, pasando por los verdes, marrones y grises al azar el negro, para teñir la lana y el algodón, con los cuales confeccionaron los famosos mantos. Llegaron a desarrollar una técnica tintorera única, empleando plantas como el Schimus molle, Berberis $s p$, Baccharis $s p$ y Eupatorium $s p$, Relbuniun hypocarpium, Indigóferas $s p$.

Según Thompson y Murillo (6), la experimentación de las plantas lleva un proceso de varias semanas, sumado a la preparación de la materia prima y el uso de varios instrumentos para el control de calidad. Los mordientes utilizados son el bicarbonato de sodio (polvo de hornear) y cloruro de sodio (sal común), adicionándolos en el momento de extracción del tinte y a la hora de fijarlo a la pulpa.

Según Carranza (2), los colorantes pueden clasificarse en función de su origen (natural o sintético), o en función de la forma en la que actúa para adherirse a la fibra: básicos, ácidos, al mordiente y reactivos. Los colorantes básicos se caracterizan por ser sales de aminas complejas que forman enlaces iónicos con los grupos ácidos de las fibras proteicas. Los colorantes ácidos funcionan en forma similar, solamente que el colorante es una sal de ácido y forma enlaces iónicos con grupos básicos de las fibras. Los colorantes al mordiente utilizan un metal, óxido o compuesto que actúa como ligamento entre la fibra y el colorante (los cuales en forma natural tienen poca afinidad), formándose un complejo que es muy resistente al lavado. Por último, los colorantes reactivos contienen grupos capaces de formar enlaces covalentes o puentes, reaccionando químicamente con la fibra textil durante el proceso de teñido, transformándose así en parte física de la misma.

\section{MÉTODOS Y RESULTADOS}

\section{Glosario}

- Serigrafía Textil (estampado textil): es una técnica de impresión empleada en la reproducción de gráficos sobre telas generalmente de punto, y consiste en transferir una tinta a través de una malla tensada en un bastidor, el paso de la tinta se bloquea en las áreas donde no habrá imagen, mediante una emulsión o barniz, quedando libre la zona donde pasará la tinta (cada color a usar, debe contar con su propio bastidor), después de dicho proceso se debe termo fijar. El estampado se puede realizar sobre tela natural o sintética, se puede obtener colores vivos con resistencia y permanencia al aire libre, se cuenta con una variedad de tintas que permite obtener acabados con colores saturados, transparentes, fluorescentes, brillantes, mates o semibrillantes.

- Tintes Textiles: son sustancias químicas que tienen la propiedad de transferir color a las fibras. Para que un tinte sea útil, debe ser capaz de unirse fuertemente a la fibra, al ser lavado no debe perder su color, debe ser relativamente estable químicamente y soportar adecuadamente la acción de la luz. Generalmente se clasifican en tintes orgánicos y en tintes sintéticos.

- Insumos Ecológicos: son materiales biodegradables e inocuos para los animales, las personas y el ambiente, que unidos a unas buenas prácticas en el proceso de producción dan como resultado productos de alto valor biológico. Fertilizantes y abonos orgánicos, semillas de producción ecológica, material de propagación vegetal, agentes de control biológico: feromonas, atrayentes, preparados de microorganismos, oligoelementos, insecticidas y fungicidas a base de plantas son algunos de los productos de la variada oferta que se puede encontrar en el mercado.

La producción de insumos orgánicos se basa en el uso de ingredientes o materias primas, admitidas en los estándares de IFOAM (Internacional Federation of Organic Agriculture Movements) para la agricultura orgánica. 
- Etiqueta Verde: dentro de la Unión Europea se ha creado una etiqueta única y obligatoria que certificará que el producto que la lleve ha pasado los exigentes controles europeos para con el medio ambiente. De este modo se facilitará el consumo de estos productos que se consideren buenos para la salud ambiental y para los consumidores, esta identificación permitirá elegir como una mejor opción entre la población que ha tomado en estos últimos tiempos una cultura ambiental.

\section{LA SERIGRAFÍA TEXTIL ARTESANAL}

Los procedimientos involucrados en la creación de las imágenes serigrafiadas se clasifican en tres áreas principales de producción: preparado del bastidor con el grabado respectivo, proceso de estampado y limpieza-almacenamiento y/o recuperación de bastidores para un nuevo grabado (Figura N. ${ }^{0} 1$ ).

El avance de la tecnología en la serigrafía artesanal se ve reflejada en el diseño de las imágenes (mejores herramientas en los software de diseño), y la aparición de diversos tintes con colores y características especiales.
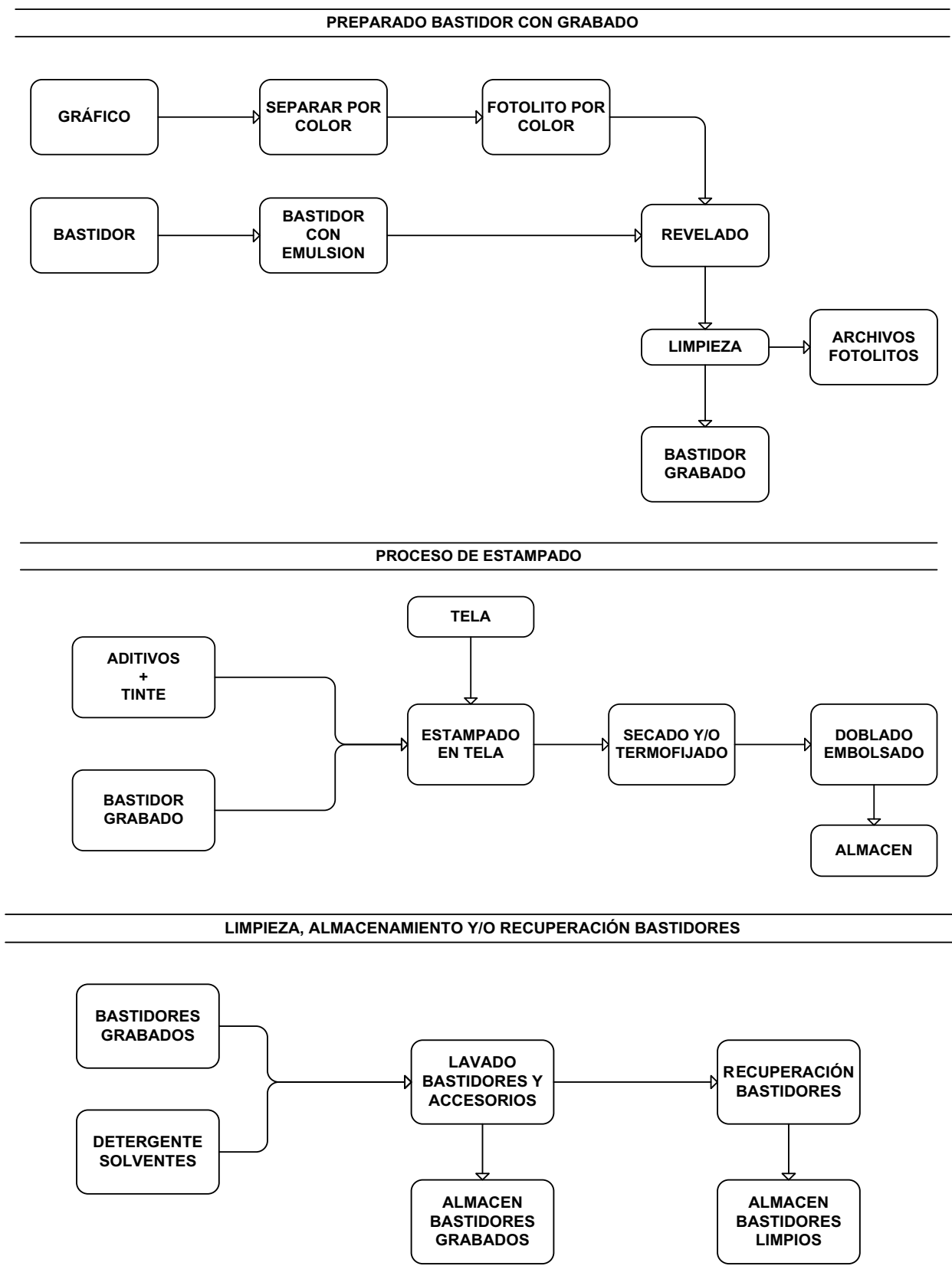

Figura N. ${ }^{\circ}$. Diagrama de del proceso de estampado. 
Características de la serigrafía textil artesanal:

- Relativa simplicidad del proceso y del equipamiento, lo que permite operar con sistemas completamente manuales.

- Es rentable en tirajes cortos y largos.

- El área de trabajo es mínima (12 a $20 \mathrm{~m}^{2}$ ).

- Informalidad.

- Inexistencia de una cultura de calidad.

- Carencias de estrategias de márketing.

- Falta de financiamiento.

- Producción orientada al mercado informal.

- No reciben apoyo de parte del gobierno.

- Negocios son familiares.

- Centros de producción, sus propias viviendas.

- En la mayoría de casos utilizan tintes sintéticos.

- La prenda que más se estampa son los polos en tela plana (según encuesta se estima que el
$76.5 \%$ de la población de Lima Metropolitana usa polos estampados, tabla 1).

- Aplican las nuevas tendencias con efectos: fantasía, texturas. terciopelo, laminados, emulan cartón, metal, arena, piedra, tacto cero, brillos, 3D.

- Se trabaja en la modalidad de tercerización.

- Trabajadores ayudantes sin mayor experiencia.

- Gráficos bajados de internet con acondicionamientos.

- Se trabaja principalmente con el software Corel DRAW.

- Hay muchos lugares que dan el servicio de diseño.

- Se usan pocos colores (cada color implica un bastidor), normalmente 4 colores.

- El arte se imprime en papel vegetal (uno por cada color).

Tabla N. ${ }^{\circ}$ 1: Porcentaje de tiendas por distritos que venden polos estampados.

\begin{tabular}{|c|c|c|c|c|c|c|c|}
\hline \multirow[t]{2}{*}{ DISTRITOS } & \multicolumn{2}{|c|}{$\begin{array}{c}\text { TIENDAS QUE } \\
\text { VENDEN ROPA }\end{array}$} & \multicolumn{2}{|c|}{$\begin{array}{l}\text { TIENDAS QUE } \\
\text { VENDEN POLOS } \\
\text { ESTAMPADOS }\end{array}$} & \multirow{2}{*}{$\begin{array}{c}\begin{array}{c}\text { POLOS } \\
\text { EXHIBIDOS }\end{array} \\
\text { CANT. }\end{array}$} & \multicolumn{2}{|c|}{$\begin{array}{c}\text { POLOS } \\
\text { EXHIBIDOS } \\
\text { ESTAMPADOS }\end{array}$} \\
\hline & CANT. & $\%$ & CANT. & $\% *$ & & CANT. & $\%^{*}$ \\
\hline LA VICTORIA & 401 & 27.7 & 250 & 62.3 & 14250 & 10825 & 76.0 \\
\hline BREÑA & 20 & 1.4 & 12 & 60.0 & 524 & 394 & 75.2 \\
\hline SAN JUAN DE LURIGANCHO & 130 & 9.0 & 97 & 74.6 & 1966 & 1488 & 75.7 \\
\hline SAN MARTÍN DE PORRES & 60 & 4.1 & 17 & 28.3 & 640 & 506 & 79.1 \\
\hline LOS OLIVOS & 60 & 4.1 & 41 & 68.3 & 891 & 581 & 65.2 \\
\hline COMAS & 82 & 5.7 & 68 & 82.9 & 1145 & 901 & 78.7 \\
\hline JESÚS MARÍA & 252 & 17.4 & 140 & 55.6 & 1250 & 795 & 63.6 \\
\hline CERCADO DE LIMA & 35 & 2.4 & 20 & 57.1 & 725 & 541 & 74.6 \\
\hline SANTA ANITA & 37 & 2.6 & 30 & 81.1 & 1402 & 1125 & 80.2 \\
\hline RÍMAC & 15 & 1.0 & 10 & 66.7 & 550 & 396 & 72.0 \\
\hline PUENTE PIEDRA & 46 & 3.2 & 34 & 73.9 & 700 & 548 & 78.3 \\
\hline VILLA EL SALVADOR & 25 & 1.7 & 15 & 60.0 & 353 & 289 & 81.9 \\
\hline SURQUILLO & 10 & 0.7 & 6 & 60.0 & 235 & 175 & 74.5 \\
\hline ATE VITARTE & 25 & 1.7 & 17 & 68.0 & 892 & 759 & 85.1 \\
\hline CALLAO & 50 & 3.5 & 38 & 76.0 & 1650 & 1265 & 76.7 \\
\hline CHORRILLOS & 19 & 1.3 & 13 & 68.4 & 385 & 298 & 77.4 \\
\hline SAN JUAN DE MIRAFLORES & 24 & 1.7 & 15 & 62.5 & 390 & 312 & 80.0 \\
\hline INDEPENDENCIA & 10 & 0.7 & 7 & 70.0 & 195 & 173 & 88.7 \\
\hline LURIGANCHO CHOSICA & 145 & 10.0 & 117 & 80.7 & 2624 & 1857 & 70.8 \\
\hline TOTAL & 1446 & 100 & 947 & & 30767 & 23228 & 76.5 \\
\hline
\end{tabular}

Porcentaje referido al total del distrito.

(Encuesta aplicada entre marzo-abril del 2010). 
- Generalmente trabajan con grabados de uno a cuatro colores.

- Se encuentran ubicados cerca a centros de producción de ropas.

- Según la encuesta realizada por el grupo de investigación en el mes de mayo del 2010 a los compradores de insumos para serigrafía, se obtuvo: con relación al tipo de tinte que utilizan, el $100 \%$ de los encuestados usan tintes sintéticos, el $7 \%$ de los encuestados manifestó que adicionalmente utilizan tintes al agua. Con relación al equipo predominante que usan, el $64 \%$ de los encuestados manifiesta que usa bastidor simple, el $6 \%$ usa bastidor con garras y el $2 \%$ manifestó que usan pulpo de 4 bastidores. Con relación a los desechos, el 100\% manifestó que botan al desagüe (Tabla N. ${ }^{\circ} 2$ ).

Según la encuesta realizada por el equipo investigador en el mes de abril 2010, en el conglomerado de Gamarra, con una muestra de 20 tiendas dedicadas a la venta de polos (750 prendas estampadas), se obtuvo los siguientes resultados: el $7 \%$ de las prendas son para bebés, el $23.4 \%$ son para niños y el $69.6 \%$ son para adultos (Tabla N. ${ }^{\circ} 3$ ).

Según otra encuesta realizada por el equipo investigador en el mercado de Gamarra, con una muestra de 300 entrevistados (personas que transitaban por la zona y que utilizaban polos estampados) se obtuvo los siguientes resultados: el $89.3 \%$ de los encuestados usan el polo en contacto directo con el cuerpo, el $10.7 \%$ utiliza el polo encima de otra prenda (Tabla N. ${ }^{\circ} 4$ ), algunos de los usuarios podrían ser alérgicos a algunos componentes de los tintes sintéticos, lo que resalta la importancia de los tintes ecológicos.

\section{Equipos usados en la serigrafía textil}

Los equipos usados en la serigrafía varían de acuerdo a la cantidad de prendas a producirse, la calidad, el tiempo de producción y la inversión.

Las MYPE serigráficas generalmente comienzan a trabajar con el método directo manual (inversión base S/.700), posteriormente adquieren una máquina serigráfica semiautomática llamada pulpo (el tamaño está relacionado al número de brazos), los precios pueden variar de S/.2 000 a S/.20 000 .

Los tintes serigráficos son de dos tipos: Base PVC plastisoles (Resinas de poli cloruro de vinilo) y base agua. Los tintes industriales están compuestos de:

- Resinas (formaldehido - sustancia cancerígena),

- Plastificantes (ftalatos - provocan cáncer, lesiones renales y desequilibrio en el sistema hormonal),

- Pigmentos (base metales pesados),

- Estabilizantes (plomo o cadmio - tóxicos),

- Solventes (benzol: inflamable, ataca glóbulos rojos),

- Emulsionantes (alquilfenoles etoxilados),

- Otros aditivos (espesantes, fijadores, retardadores, etcétera).

Las MYPE serigráficas usan tintes sintéticos importados, los cuales se encuentran solubilizados en solventes orgánicos, generalmente aromáticos, (considerados como compuestos orgánicos persistentes), sin embargo no se prevén las consecuencias del uso de estos solventes, habida cuenta que

Tabla N. ${ }^{\circ}$ 2: Tipo de tinte y equipo usado en serigrafía y lugar de los desechos

\begin{tabular}{|c|c|c|c|c|c|c|}
\hline & \multicolumn{2}{|c|}{ Tipo de tinte } & \multicolumn{3}{|c|}{ Equipo } & \multirow{2}{*}{$\begin{array}{c}\text { Desechos } \\
\text { al } \\
\text { desagüe }\end{array}$} \\
\hline $\begin{array}{c}\text { Nro. } \\
\text { Encuestados }\end{array}$ & Al agua & Sintético & $\begin{array}{c}\text { Bastidor } \\
\text { simple }\end{array}$ & $\begin{array}{c}\text { Bastidor } \\
\text { garras }\end{array}$ & Pulpo & \\
\hline 50 & 7 & 50 & 34 & 12 & 4 & 50 \\
\hline $100 \%$ & $14 \%$ & $100 \%$ & $64 \%$ & $24 \%$ & $8 \%$ & $100 \%$ \\
\hline
\end{tabular}

Tabla N. ${ }^{\circ}$ 3: Número de prendas estampadas en exhibición.

Tabla N. 4: Uso del polo estampado.

\begin{tabular}{|c|c|c|c|c|}
\hline \multirow{2}{*}{$\begin{array}{c}\text { Tiendas } \\
\text { encuestadas }\end{array}$} & \multirow{2}{*}{$\begin{array}{c}\text { Prendas } \\
\text { estampadas }\end{array}$} & \multicolumn{3}{|c|}{ Tipo de usuario } \\
\cline { 3 - 5 } & & Bebé & Niño & Adulto \\
\hline 20 & 750 & 52 & 176 & 522 \\
\hline Porcentajes & $100 \%$ & $7 \%$ & $23.4 \%$ & $69.6 \%$ \\
\hline
\end{tabular}

\begin{tabular}{|c|c|c|}
\hline Encuestados & $\begin{array}{c}\text { Polo en contacto } \\
\text { directo }\end{array}$ & $\begin{array}{c}\text { Polo sobre } \\
\text { otra prenda }\end{array}$ \\
\hline 300 & 268 & 32 \\
\hline $100 \%$ & $89.3 \%$ & $10.7 \%$ \\
\hline
\end{tabular}


éstos ingresan fácilmente al organismo por diferentes vías iniciando una serie de enfermedades respiratorias y digestivas, y contaminan el ambiente. Las recomendaciones de los consumidores extranjeros, especialmente el europeo es que las prendas deben tratarse con tintes orgánicos o naturales, no de producción química o sintética, siguiendo las especificaciones de los agentes certificadores oficiales. Las etiquetas ecológicas son una manera de comprobar que la ropa se ha producido respetando el medio ambiente, también se viene afirmando en lo referente al consumo de ropa la aplicación de la política de las $3 R$ (reducir, reutilizar, reciclar).

Los residuos o basura de los talleres serigráficos (Tabla N. ${ }^{\circ} 3$ ) en sus diversas presentaciones provoca contaminación en diversas formas: los agentes líquidos forman parte de las aguas negras, los desechos industriales (residuos de pintura), los derrames de combustibles derivados del petróleo (solventes y limpiadores), los cuales dañan las aguas de los desagües que van a dar a ríos y océanos, además los agentes gaseosos (solventes y limpiadores) que directamente pasan al ambiente.

Una de las dificultades que tienen las MYPE de serigrafía textil es el matizado de los tintes debido a que los insumos varían en marca y calidad, las tonalidades de los gráficos son abundantes y el comprador exige colores similares a las fotográficas o muestras.

\section{Utilización de motivos nacionales para el estam- pado}

Los dibujos a usarse en el estampado varían constantemente, depende de la moda (programas televisivos, películas de estreno, etcétera). Estos dibujos generalmente se obtienen por Internet.

Considerando conveniente crear una cultura peruana, en la Facultad de Ingeniería Industrial de la UNMSM se ha formado un banco de gráficos, que serán mostrados en el campo virtual de la institución, dicho banco irá incrementándose con el aporte de los alumnos.

\section{TINTES NATURALES}

Los tintes naturales, también llamados ecotintes, son aquellos que no emplean mordientes tóxicos como cromo, estaño ni cobre, además utiliza auxiliares naturales de bajo o nulo impacto ecológico. A manera de regla, los tintes naturales se extraen de las diferentes partes de las plantas (hojas, tallos, raíces, cortezas), pulverizándolas, desmenuzándolas o cortándolas. Las partes de la planta luego son colocadas en agua calentada a una temperatura justo por debajo del punto de ebullición hasta que el color se haya transferido al agua. Cuando el color es añadido a un material saturado en mordiente, el tinte se adhiere entonces a la fibra del material. En el imperio inca los encargados de teñir con tintes naturales eran los canticamayoc, en los aclla huasi y obrajes femeninos, las mamaconas se dedicaban a confeccionar las prendas de vestir.

Para conocer la situación de los tintes naturales en el Perú se realizaron cinco visitas a lugares que según información ubicada en internet usaban tintes naturales.

En la ciudad del Cusco, en general, en las tiendas de productos de artesanías, solo dos quioscos vendían escasos productos teñidos con tintes naturales.

Las conclusiones más importantes de estas visitas son:

- La tradición pre inca e inca sobre el uso de tintes naturales se está perdiendo debido al uso de productos sintéticos.

- Los colores obtenidos por los productos naturales en general tienen baja tonalidad.

- Los costos de las prendas textiles teñidas con tintes naturales cuestan de 2 a 3 veces más que las teñidas con tintes sintéticos.

- Hay deforestación de las plantas con propiedades tintóreas.

- Se usan teñido de lanas con anilinas, por su facilidad.

- Falta de enseñanza a la población sobre teñido a partir de plantas tintóreas.

Los colorantes naturales más usados en el Perú son:

- Cochinilla: (ácido cumínico) guindo, rojo y rosa

- Eucalipto: amarillo, anaranjado, marrón y beige.

- Maíz morado: rojo, violeta y azul.

- Molle: verde, amarillo y gris azulado.

- Muña: amarillo y gris.

- Nogal: marrón y beige.

- Tara: verde pacay, azul, plomo y marrón.

Los mordientes facilitan la fijación del tinte a la fibra, la uniformidad del teñido y da brillo. Entre los mordientes más usados tenemos:

- Alumbre (sulfato de aluminio)

- Crémor tártaro (ácido de potasio) 
- Caparrosa (sulfato de hierro y sulfato de cobre)

- Collpa (salitre, ceniza, arcilla y barro negro)

- Sal de mesa, limón, vinagre

- Tara, chicha de jora, pepa de palta

La característica particular que deben tener los tintes para serigrafía es su viscosidad. Los componentes de una tinta para serigrafía son: colorante, base, fijador, conservador y diluyente.

En los ensayos realizados para obtener un tinte natural para el proceso de estampado se ha trabajado con la tara (Caesalpinia spinosa), chinchango (Hypericum laricifolium) y el eucalipto (Eucalyptus). Se ha tenido una experiencia favorable con el eucalipto.

\section{OBTENCIÓN DE COLORANTE NATURAL DE LAS HOJAS DE EUCALIPTO}

Por información de personas mayores y folletos artesanales, el tinte de eucalipto tiene mejor adherencia y por la facilidad de poder conseguir ramas frescas de dicha planta se escogió para su análisis en laboratorio.

Para la obtención del tinte de las hojas de eucalipto, se hicieron pruebas con hojas tiernas y hojas maduras de eucalipto, para lo cual se remojaron $100 \mathrm{~g}$ de hojas en 2 litros de agua por espacio de una semana observándose que conforme transcurre el tiempo, el agua de remojo va tomando color. Luego esta mezcla se lleva a ebullición por espacio de 90 minutos hasta obtener una solución oscura, se filtra la mezcla obteniéndose $250 \mathrm{ml}$ de tinte $(\mathrm{pH}$ : $4,78)$, apto para ser utilizado tanto como colorante de prendas como para la aplicación en serigrafía. Se observa que el color obtenido de las hojas tiernas es verde, mientras que de las hojas maduras se obtiene un color marrón.

\section{Teñido de tela de algodón}

Para este propósito se tomó $20 \mathrm{ml}$ de tinte y se añade agua (hasta $100 \mathrm{ml}$ ), se calienta hasta $60^{\circ} \mathrm{C}$ y se adiciona la muestra de algodón a teñir, se calienta hasta $80^{\circ} \mathrm{C}$ y se mantiene esta temperatura por espacio de 45 minutos, al cabo de los cuales se añade el sulfato de aluminio (que actúa como mordiente), el peso del sulfato es $25 \%$ del peso del algodón; se tiñe por 30 minutos adicionales, se retira la prenda y se enfría. Se observa un buen color en la muestra, para verificar la tinción se lava dos veces con detergente, disminuyendo el color en muy poca proporción. En la Figura $\mathrm{N}^{\circ}{ }^{2}$, se presentan las muestras teñidas.

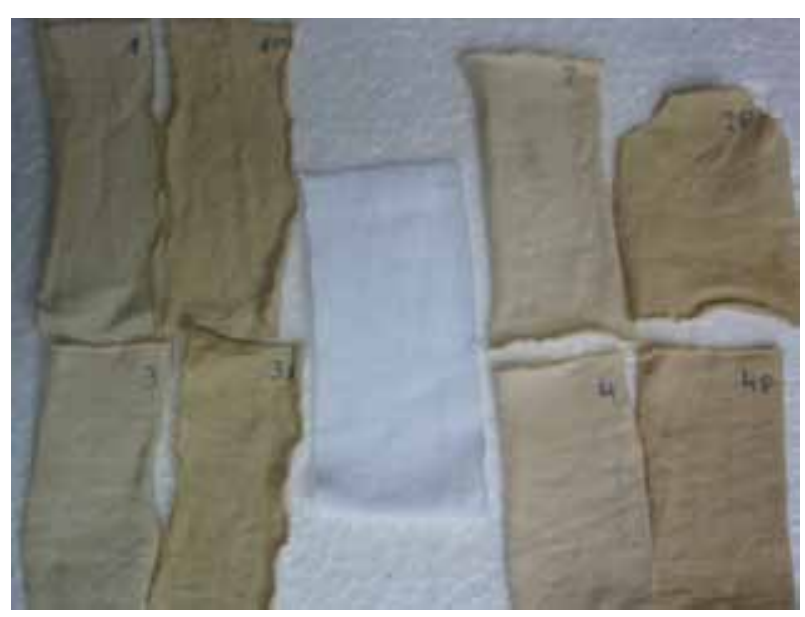

Figura N.․ 2. Telas de algodón teñidas con eucalipto.

Las recomendaciones de los consumidores extranjeros, especialmente el europeo, es que las prendas deben tratarse con tintes orgánicos o naturales, no de producción química o sintética, siguiendo las especificaciones de los agentes certificadores oficiales.

\section{RESULTADOS Y ANÁLISIS}

Para la obtención de tinte natural para serigrafía a partir del eucalipto, se realizaron pruebas con distintas sustancias para obtener un vehículo adecuado para el tinte (copage, sustancia base, maicena, harina, almidón, etcétera). Este vehículo tenía que tener una viscosidad adecuada para poder ser manipulada fácilmente en la prenda.

Los equipos utilizados fueron: colorímetro, cromatógrafo, termómetro, estufa de laboratorio, peachímetro y microscopio.

Se obtuvo una suspensión de almidón en agua, calentada previamente y luego enfriada con las características necesarias de viscosidad.

Las cantidades adecuadas para obtener el tinte fueron:

- $30 \mathrm{ml}$ del colorante de eucalipto

- $2 \mathrm{ml}$ de una solución de sulfato de aluminio

- $100 \mathrm{ml}$ de la suspensión de almidón

Se uniformiza la mezcla por 5 minutos, hasta obtener una pasta.

Se aplicó al proceso de estampado.

Se procedió al fijado de la tinta con pistola secadora por tres minutos. 
Se aplicó el lavado con detergente y se dejó secar en forma natural, se notó una pérdida de color mínima.

Después de 2 días se procedió a lavar con detergente por segunda vez, ya no es perceptible la pérdida de color.

El producto final obtenido muestra una aplicación uniforme con solidez al lavado (Figura N. ${ }^{\circ} 3$ ).

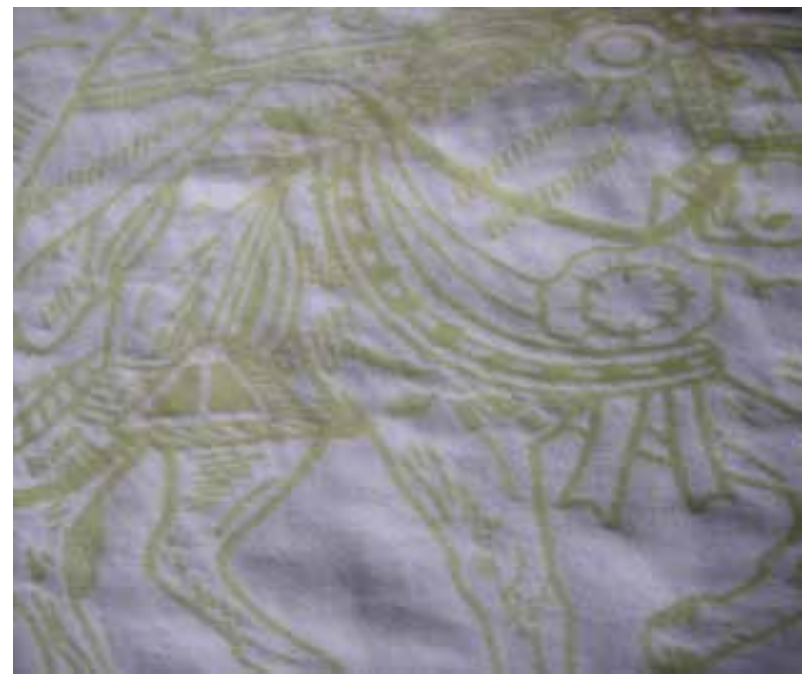

Fuente: Elaboración propia

Figura N. ${ }^{\circ}$ 3: Estampado con tinte de eucalipto, vehículo almidón.

\section{CONCLUSIONES}

- Se estima que el $76.5 \%$ de polos que se comercializan en la Ciudad de Lima son estampados.

- La industria de la serigrafía de las MYPE utilizan tintes sintéticos principalmente por su facilidad de uso.

- Se están perdiendo los conocimientos del trabajo de teñido textil con tintes naturales.

- No existe una cultura ambientalista y de salud ocupacional en el personal que trabaja en serigrafía.

- La universidad debe tener una mayor sensibilidad a las necesidades de la sociedad, por lo que los currículos académicos deben ser flexibles y adaptarse con las necesidades del desarrollo económico, tecnológico y social del país.

- Es posible obtener una mezcla de vehículo y colorante natural concentrado con el correspon- diente mordiente, para usarlo en serigrafía. En la aplicación de esta mezcla no se genera residuos, por tanto el proceso es inocuo al medio ambiente.

- Se hace necesario seguir con la investigación de obtención de tintes naturales a partir de otras materias primas, en coordinación con los campesinos, quienes conocen las propiedades colorantes de muchas plantas, y en su aplicación, dependiendo del tipo de planta, se hace uso de hojas, tallos, raíces o cortezas.

Se requiere caracterizar la pasta conformada por el tinte, vehículo y mordiente, a través de la determinación de parámetros fisicoquímicos, tales como su absorbancia, densidad y viscosidad.

En los tintes naturales, no es posible reproducir un tono exacto de color, pues hay muchas variables involucradas, tales como el lugar de procedencia, el grado de madurez de la planta cuyas hojas, tallos y cortezas se utilizan.

\section{REFERENCIAS BIBLIOGRÁFICAS}

[1] Barboza Palomino, G (2007). Acción de los mordientes o fijadores en el proceso de teñido artesanal con tintes naturales, Universidad San Cristóbal de Huamanga, Ayacucho, Perú.

[2] Carranza Forkel, I (2005).Colorantes y métodos de tinción en la artesanía textil guatemalteca. Universidad de San Carlos de Guatemala, Facultad de Humanidades. Guatemala. http://biblioteca.usac.edu.gt/tesis/07/07_1513.pdf. (Visitada el 2-12-2010).

[3] Gibaja, S (1998). Pigmentos naturales. Universidad Nacional Mayor de San Marcos Lima, Perú.

[4] Gómez Orozco, D (2004). Comparación del porcentaje de extracto tánico de la corteza y de la madera de encino (Quercus tristis Liebm) proveniente de un bosque natural. Universidad de San Carlos de Guatemala-Facultad de Ingeniería. Guatemala.

[5] Proyecto Ministerio de Educación-Ministerio Comercio Exterior y Turismo (2006). Guía de proyectos Tintes Naturales. Lima, Perú.

[6] Thompson Vicente, Elizabeth; Murillo Herrera, Alberto. Investigación de tintes derivados de plantas comunes para ser usadas con fibras celulósicas. http://www.kerwa.ucr.ac.cr/handle/10669/367. Visitada el 15-11-2010. 